\title{
ОЦЕНКА И РЕГУЛИРОВАНИЕ РИСК-АППЕТИТА БАНКА
}

\begin{abstract}
EVALUATION AND REGULATION
OF THE BANK'S RISK APPETITE
I. Vasilyev

Summary. The income of commercial banks and their level of economic security are a manifestation of the risk to which they will agree and take into account in the course of their activities.

Today, every credit institution operates in conditions of instability and uncertainty of the external environment and, accordingly, in a risk environment. In the process of achieving their goals, commercial banks face risk every day. All the income can earn is a manifestation of the risk to which they will agree and take into account in the course of their activities.

Thus, each commercial bank determines the result that it hopes to get. This result is the starting point for the formation of a portfolio of strategic directions for its development. In this context, it is important to determine how much risk is acceptable to achieve these goals. This uses the concept of risk appetite, which allows establishing a balance between the desired result and the possible danger in the process of achieving goals.
\end{abstract}

Keywords: risk-appetite, risk neutralization, banking risks, risk-management, banking services.

\author{
Васильев Игорь Иванович \\ К.э.н., дочент, Финансовый университет при \\ правительстве Российской Федерации \\ vasilev-1962@inbox.ru)
}

Аннотация. Доходы коммерческих банков и уровень их экономической безопасности являются проявлением того риска, на который они согласятся и учтут в процессе своей деятельности. Для этого целесообразно использовать концепцию риск-аппетита, которая позволяет установить баланс между желаемым результатом и возможной опасностью в процессе достижения целей. Обязательным условием укрепления безопасности экономической деятельности коммерческого банка является оценка и нейтрализация рисков, опасностей и угроз.

Сегодня каждая кредитная организация работает в условиях нестабильности и неопределенности внешней среды и, соответственно, в условиях риска. В процессе достижения своих целей коммерческие банки сталкиваются с риском каждый день. Все доходы, которые они могут получить, являются проявлением того риска, на который они согласятся и учтут в процессе своей деятельности.

Таким образом, каждый коммерческий банк определяет результат, который он надеется получить. Этот результат является отправной точкой формирования портфеля стратегических направлений его развития. В данном контексте важно определить, насколько риск является приемлемым для достижения данных целей. Для этого используется концепция риск-аппетита, которая позволяет установить баланс между желаемым результатом и возможной опасностью в процессе достижения целей.

Ключевые слова: риск-аппетит, нейтрализация рисков, банковские риски, риск-менеджмент, банковские услуги.

Определение риск-аппетита позволяет банкам избежать банкротства в период финансовой нестабильности.

Большие трудности, связанные с нестабильностью, которая характерна рынку финансов и банковскому сектору, как стране в отдельности и в целом на мировой арене стали динамично выражаться в конце 20 и начале 21 веков. С 90-х по 2010 гг. на мировой арене миновали три глобальных кризиса, серьезно затронувшие банковский рынок: в 1990-х годах нефтяной кризис, в 2007 году кризис на рынке недвижимости и в 2008 году кризис на рынке ипотечных ценных бумаг [1].

Чрезвычайно сильно на рынке банковских услуг сказался и отразился кризис 2008, вызвавший собой банкротство мировых гигантов. К краху этих кредитных организаций привели опрометчивые действия руководства 
по реализации инвестиционных решений, которые взвалили на себя очень высокий риск при операциях с ценными бумагами, который имели спекулятивный характер.

В первую очередь эти промахи связаны с плохо организованной работой риск-менеджмента, который в свою очередь сумел в нужный момент реализовать мероприятия для устранения финансовых убытков, давших повод для прекращения деятельности банков.

Кризисные события 2008 года повлекли за собой процедуры банкротства значимых инвестиционных банков Америки. До начала этих событий кризисные явления стали проявляться на рынке жилой недвижимости, повлекшие за собой утрату платежеспособности огромной части населения США, всё это выразилось в росте просроченных ссуд по ипотечным платежам, образовались задолженности по кредитам и трудности с последующей продажей недвижимого залогового имущества. Эти факты в значительно сильно отразились на работе кредитных организаций, основным видом деятельности которых было ипотечное кредитование. Все эти мировые столкновения в масштабном размере на финансовом рынке привели к актуальности развития более эффективного риск-менеджмента в коммерческом банке и к организации верного определения риск-аппетита на рынке банковских услуг [2].

Большинство банков перешли на организацию более тщательной работы по планированию своих финансовых показателей и деятельности в целом с использованием более эффективных инструментов риск-менеджмента. На фоне данных событий возникло новое понятие «риск-аппетит», именно оно становится одним из ведущих определений в банковской сфере после мировых финансовых кризисов.

Распознавание наиболее опасных рисковых ситуаций является началом в управлении банковскими рисками. Многие авторы этот этап в риск-менеджменте банка считают самым важным, так как именно он помогает более тщательно спрогнозировать и сформулировать события, которые могут повлиять на банковскую деятельность, тем самым помогут решить проблемы наступления финансовых трудностей и помогут сформировать правильную стратегию управления банковскими рисками.

Сформировать перечень данных рисков предпочтительно с помощью мнения экспертов, которые являются квалифицированными специалистами в данной области и имеют достаточный стаж работы. К ним относятся как сотрудники подразделений риск-менеджмента, так и сотрудники других отделов, не связанных напрямую с управлением банковскими рисками.
После создания значимых рисков их необходимо разбить на группы и на каждую группу назначить ответственного исполнителя того или другого подразделения коммерческого банка. Именно на этом этапе устанавливается корректный уровень «аппетита к риску».

В практике международного управления рисками «аппетит к риску» - принимается как максимально допустимой уровень риска, где кредитная организация готова нести для достижения необходимого дохода.

Указание ЦБ РФ от 15.04.2015 № 3624 - У (ред. от 03.12.2015) «О требованиях к системе управления рисками и капиталом кредитной организации и банковской группы» применяет определение «склонность к риску», именно он является близким по значению к определению «аппетит к риску». Но данное понятие при различных интерпретациях на сегодняшний день носит дискуссионный характер [3].

Многие эксперты доказывают, что необходимо отличать понятия и термины «аппетит к риску», «толерантность к риску», «границы риска» и «переносимость риска». Также следует подчеркнуть, что определение «аппетит к риску» достаточно активно используют в своей деятельности не только кредитные организации, но и коммерческие организации.

В практической деятельности банков к определению понятия «аппетит к риску» используются различные мнения. Например, в документе («Информация о принимаемых рисках, процедурах их оценки, управления рисками и капиталом группы ВТБ») риск-аппетит трактуется как «количественная и качественная система показателей, которая устанавливает целевой профиль рисков, «группа ВТБ может принять с учетом обязательств, выставленных заинтересованными лицами чтобы получить установленные стратегические целевые ориентиры».

Нормативный документ ПАО Сбербанк «Стратегия управления рисками и капиталом Группы ПАО Сбербанк», делает упор на более широкое понятие «аппетита к риску» как «системы показателей, которые показывают риск по максимуму, который Банк могут принять при создании стоимости, получения установленных целевых ориентиров, в том числе необходимого уровня доходности, выполнения стратегических инициатив и реализации своей главной миссии». Данное определение является наиболее оптимальной, так как собирает в себе не только несколько первоочередных понятий определения, но и предполагает взять на вооружение значимый принцип VBM (Value Based Management) -установление для акционеров стоимости [4]. 
В процессе управления банковскими рисками установка корректного определения риск-аппетита считается значимым звеном выстраивания эффективной стратегии управления рисками кредитной организации. Зачастую причиной высокого риск-аппетита кредитная организация встречается образование просроченных задолженностей, уменьшением стоимости активов, снижением ликвидности, что приводит к неодобрительной ситуации вкладчиков и бегство капитала. Снятие денежных средств с депозитов приводит кредитную организации к еще более серьезным проблемам и по итогу может привести к ликвидационным (банкротство) процедурам, либо организацией управления сторонними органами и вступлением в процесс оздоровления коммерческого банка (санация).

Рост наступления роста числа плохих займов считается стремлением банка повысить доходы посредствам предоставления кредитов клиентам с несоответствующей историей по кредитам и значительным риском, связанным с утратой платежеспособности. В данном случае для таких клиентов устанавливается «премия за риск» в виде более высокой процентной ставки, которая выступает как источник дополнительного процентного дохода. Но зачастую уровень данного риска не соответствует реализуемой банком стратегии развития.

В российской банковской практике сегодня существует огромное количество примеров необоснованных действий, которые обратились в серьёзные проблемы и повлияли негативно на ликвидность и собственный капитал кредитной организации. Следует отметить, что наличие данных трудностей в кредитной организации выявляются чаще всего только после проверок надзорных органов или компаний, оказывающих аудиторские услуги.

Отрицательным моментом в деятельности кредитных организаций является пренебрежение более тщательной проверки заемщика на действительный его вид деятельности. Удостовериться в том, что клиент, нуждающийся в займе, ведет свой бизнес в рамках определенного промежутка времени, например, за последний год можно, при помощи запроса платежного документа об уплате налогов на обозначенную сумму. Как правило, это установленный процент от суммы лимита, который открыт на заемщика. Также подтверждающим фактором реального ведения бизнеса может быть факт предоставления заемщиком бухгалтерской отчетности в налоговые органы за квартальный период. Так как приема налоговой инспекцией отчетности от заемщика является стопроцентным подтверждением его деятельности в реальности.

Невыполнения процедуры проверки деятельности заемщика в реальности может свести к тому, что де- нежные средства, которые кредитная организация предоставляет посредствам займа, могут быть извлечены со счетов заемщика либо на счета дочерних компаний или партнеров, либо напрямую основному бенефициару предпринимателю.

Потребность собственников и руководителей кредитных организаций повысить доходы может привести к неутешительным проблемам, которые проявятся в потере прибыли от основной деятельности по банковским операциям - предоставлении кредитов и оформлении, и открытии депозитных счетов.

Одной из значимых ролей в деятельности собственников банка и его руководства считается желание строго действовать в рамках стратегии его развития. Именно поэтому на первый план выходит построение продуктивного механизма в управлении банковскими рисками.

При плохо организованной системе управления рисками банк прекращает соблюдать обязательные нормативы, на которые устанавливает требования ЦБ РФ, которые вызваны, прежде всего, уменьшением собственного капитала и недостаточным количеством ликвидных активов. Всё это приводит к отзыву (лишению) лицензии на право заниматься банковской деятельностью, либо руководство банком переходит внешним управленцам, то есть под контроль внешних надзорных органов [5].

Можно сделать вывод, грамотно диагностированный риск-аппетит и отчетливые действия в политике управления банковскими рисками смогут оказать большому количеству кредитных организаций миновать проблемных ситуаций, снижающих их ликвидность, тем самым предотвратить в банковском секторе отзыв лицензий.

Однако, следует помнить, что большинство кредитных организаций принадлежат бизнесменам, которые занимаются параллельно развитием в других экономических отраслях, что приводит к выводу денежных средств из организации при помощи третьих лиц. Всё это в большей степени увеличивает банковские риски, которые негативно отражаются на развитии кредитной организации и банковском секторе страны в целом. Всё это вынуждает Банк России применять более ужесточенные меры по восстановлению всей банковской отрасли за счет отзыва лицензий большого количества коммерческих банков.

Риск-менеджмент одно из важных направлений в эффективной деятельности работы банка. Правильность определения риск-аппетита позволяет банкам избежать процедуры банкротства (ликвидационных процедур) в период финансовой нестабильности. 
ЛИТЕРАТУРА

1. Шереметьева, М.П. Банковский сектор РФ: текущее состояние и тенденции развития / М.П. Шереметьева // Молодой ученый. — 2019. — № 21 (259)

2. Зверев, А.В., Мандрон В.В., Мишина, М.Ю. Механизм санации кредитных организаций: российская практика // Финансы и кредит. 2019. № 8.c. 1727-1741.

3. Официальный сайт Банка России. // [Электронный ресурс]. — Режим доступа: https://www.cbr.ru/ (дата обращения 12.09.2020)

4. Банковская система в современной экономике: учебное пособие / коллектив авторов; под ред. О.И. Лаврушина и др.,- Москва: КноРус, 2019.c. 176

5. Артеменко Д.А., Шишков С.А. Анализ эффективности мер по предупреждению несостоятельности (банкротства) кредитных организаций // Научный вестник Южного института менеджмента. 2017. № 4. - c. 34-39.

6. «Basel IV — Emerging from the mist». KPMG. Retrieved. Мау 2016. [Электронный ресурс] — Режим доступа: https://assets.kpmg.com (дата обращения 22.09.2020)

7. Bessis Joel. Risk management in banking /J. Bessis. — John Wiley \& Sons. — 2018. — $821 \mathrm{p}$

8. Effects of Covid-19 on the banking sector: the market's assessment // Bank for International Settlements 2020. All rights reserved. Brief excerpts may be reproduced or translated provided the source is stated.— 2020.— № 12.— c. 9.

9. Risk Management Principles for Electronic Banking, Basel Committee on Banking Supervision, Bank for International Settlements, Basel. [Электронный ресурс] — Режим доступа: https://www.bis.org/publ/bcbs98.pdf. (дата обращения 21.09.2020)

(с) Васильев Игорь Иванович ( vasilev-1962@inbox.ru))

Журнал «Современная наука: актуальные проблемы теории и практики»

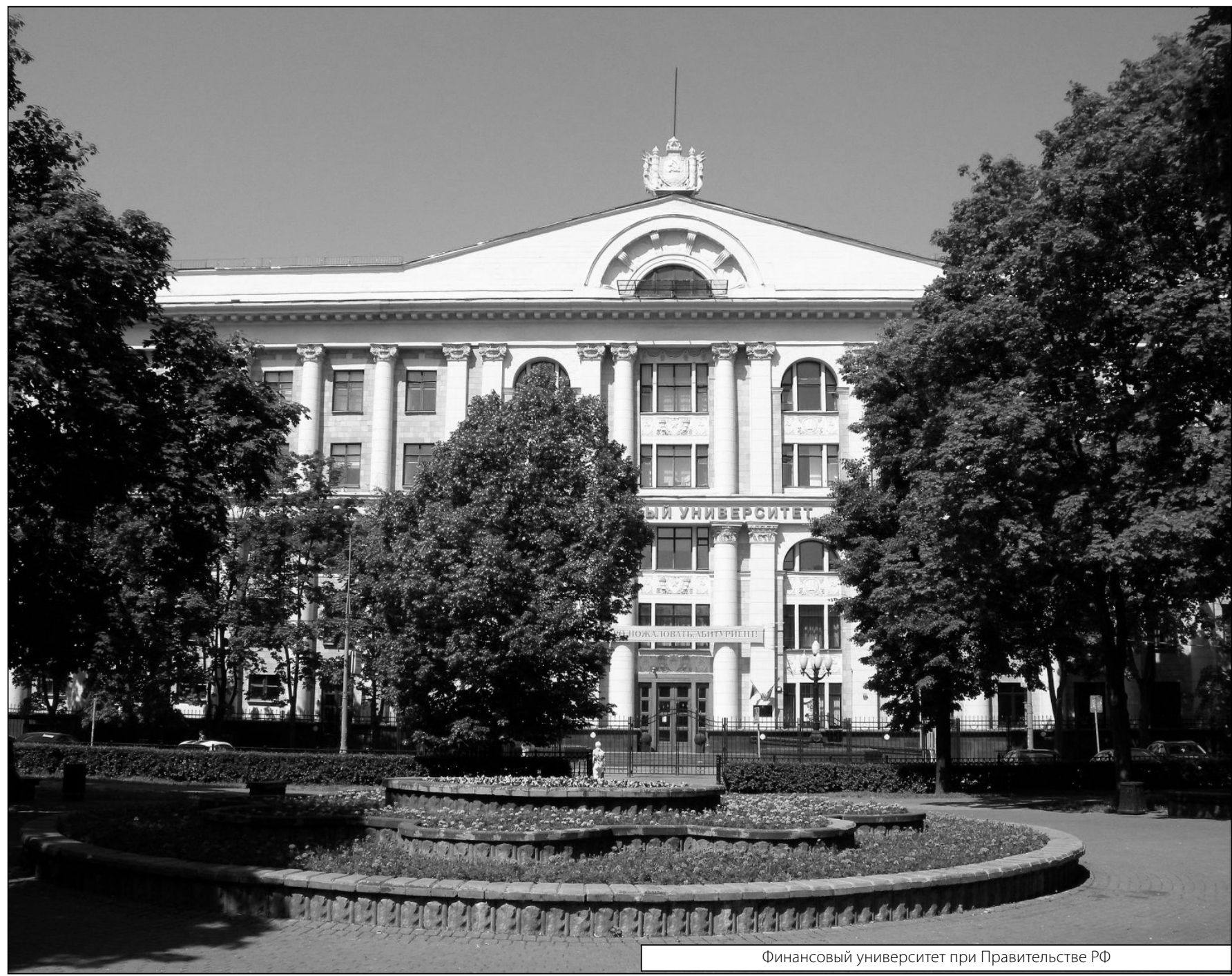

